\title{
OS LEIGOS NA OBRA CONCILIAR DO VATICANO II E NAS CONFERÊNCIAS EPISCOPAIS LATINO-AMERICANAS
}

\author{
Me. Fernando Rodrigues Francisco* \\ Dr. Maurilio Alves Rodrigues*
}

\section{RESUMO}

Neste ano comemoramos os cinquenta anos de abertura do Concílio Vaticano II. Este Concílio foi o grande incentivador dos ministérios leigos dentro da Igreja. Através de algumas de suas obras conciliares podemos identificar a missão dos leigos na prática de evangelização na lgreja e no mundo. A presença de uma teologia do laicato mais sistematizada com o Vaticano II influenciou sobremaneira as Conferências Episcopais Latino-Americanas. Na América Latina o protagonismo dos leigos vem ocupando destaque no processo de decisão da lgreja.

\begin{abstract}
This year we celebrate the fiftieth anniversary of the opening of Vatican Council II. This council was the chief proponent of lay ministries within the Church. Through some of its works council can identify the mission of the laity in the practice of evangelism in the Church and the world. The presence of a more systematic theology of the laity with the Vatican II greatly influenced the Latin American Bishops' Conferences. In Latin America the role of the laity has been occupying prominent in the decision of the Church. The presence of the laity within the church community
\end{abstract}

\footnotetext{
* Sacerdote da Diocese de Lins - SP. Possui graduação em Comunicação Social, graduação em Filosofia, graduação em Teologia, diplomado em Comunicação pela Université de Paris II, mestrado em Comunicação pela Université Catholique de Louvain (Bélgica), mestrado em Teologia pela Pontifícia Universidade Católica de São Paulo, Professor da área de Teologia Pastoral da Faculdade João Paulo II, de Marilia-SP.

** Sacerdote da Diocese de Assis - SP. Possui graduação em Filosofia, graduação em Teologia, mestrado em História pela Universidade Estadual Paulista Júlio de Mesquita Filho, em Assis-SP, mestrado em Teologia pela Université Catholique de Louvain e doutorado em Ciências Religiosas pela École Pratique des Hautes Études - Sorbonne. Atualmente é Diretor e professor titular na Faculdade João Paulo II, de Marília-SP.
} 
A presença dos leigos no seio da comunidade eclesial tem renovado a estrutura tradicional da Igreja.

Palavras-chave: Leigo, Concílio Vaticano II, Teologia do Laicato, Igreja. has renewed the traditional structure of the Church.

Keywords: Laity, Theology of the Laity, Vatican Council II, Church.

\section{INTRODUÇÃO}

As comemorações dos cinquenta anos da abertura do Concílio Vaticano II nos permitem uma salutar retrospectiva sobre muitos aspectos da vida da Igreja. Enfocaremos neste artigo um tema que continua sendo muito atual, pois diz respeito aos sujeitos privilegiados da evangelização no século XXI: os leigos.

Experiências inovadoras e sistematizações teológicas corajosas se entrecruzaram nas comissões e nas sessões conciliares, fazendo emergir um horizonte novo para a participação dos leigos na missão da Igreja.

Em muitas partes do mundo, os engajamentos concretos das organizações leigas, como por exemplo, no seio da Ação Católica (AC), haviam trazido uma série de questionamentos novos aos seus membros. ${ }^{1}$ As novas práticas de comprometimento dos católicos, seja na evangelização seja na vida social, criaram condições para o desenvolvimento de uma nova compreensão do valor dos leigos no seio da Igreja. Antes de se tornar doutrina oficial, a prática já comprovava algumas noções conciliares básicas.

\section{O CONCÍlIO VATICANO II E A MISSÃO dOS LEIGOS NA IGREJA E NO MUNDO}

Se dependesse da intenção manifestada pelo pontífice desde o início, a renovação operada pelo concílio teria sido muito maior. Vários pesquisadores evidenciaram que a maioria do episcopado insistia nas ideias de sempre, sem captar as intuições profundas que deviam desabrochar no concílio. ${ }^{2}$ João

Cf. SESBOÜÉ, B. N'ayez pas peur ! Paris: Desclée de Brouwer, 1996, p. 115.

2 Cf. LAMBERIGTS, M.; SOETENS, C. A la veille du Concile Vatican II. Leuven: Bibl. van de faculteit der Godgeleerdheid, 1992, p. 24-168.; BEOZZO, J.O. (ed.). Cristianismo y Iglesias de América Latina em vísperas Del Vaticano II. San José: DEI/CEHILA, 1992, p. 97-214.

128 Revista de Cultura TeológIcA - v. 20 - N. 79 - JUL/SET 2012 
XXIII, ao contrário, dialogava pessoal e coletivamente com muitos bispos, procurando motivá-los o mais possível para uma participação profética nos trabalhos conciliares. ${ }^{3}$

Tendo começado a 11/10/1962 e terminado, após alguns intervalos, em 07/12/1965, o Concílio Vaticano II discutiu toda a vida da Igreja e sua relação com o mundo, produzindo 16 documentos. Vários dentre eles tratam de questões relativas aos leigos: a Constituição Lumen Gentium (sobre a Igreja), a Constituição Gaudium et Spes (sobre a Igreja no mundo de hoje), o Decreto Apostolicam Actuositatem (sobre o apostolado dos leigos), o Decreto Ad Gentes (sobre a atividade missionária da Igreja), o Decreto Presbyterorum Ordinis (sobre o ministério e a vida dos presbíteros).

Este foi o concílio que mais deu espaço aos leigos em seus documentos, referindo-se a eles mais de quarenta vezes. Outra característica digna de nota foi a participação ativa dos leigos - homens e mulheres - durante os trabalhos conciliares, pela primeira vez na história moderna. No entanto, tal participação enfrentou muitas barreiras para se efetivar. Tendo tomado parte dos trabalhos conciliares, a leiga Rosemary Goldie pôde elencar vários relatos destes desafios, seja na parte de leigos como de bispos:

É muito difícil, e frequentemente impossível marcar a fonte real das mudanças empregadas nos textos (ritmo acelerado, necessidade de um intermediário influente, etc.) [...]. Os leigos foram consultados oficialmente muito pouco, e muito tarde. ${ }^{4}$

Em suas 'notas cotidianas no concílio', o teólogo Marie-Dominique Chenu nos conta que muito antes da abertura do concílio, a comissão preparatória dos leigos havia pedido por unanimidade a possibilidade de designar especialistas leigos. O presidente da comissão, cardeal Cento, enviou o pedido por escrito ao papa. A resposta jamais chegou. João XXIII afirmou ao padre Roberto Tucci - hoje cardeal - que jamais recebera tal correspondência. Dias depois, durante uma audiência com o cardeal Tardini, padre Tucci vê a carta e o relatório do cardeal Cento sobre a mesa. Indagado sobre o que se

3 Cf. AlBerigo, A.; ALBERIGO, G. Giovanni XXIII. II concilio della speranza. Padova: Ed. Messaggero, 1985, p. 61s.

4 GOLDIE, R. La participation des laïcs aux travaux du Concile Vatican II. In: Revue des Sciences Religieuses de Strasbourg. Strasbourg: [s.n.], n¹, t. 62, p. 62 e 69, 1988, tradução nossa. 
passava, Tardini responde violentamente que, segundo a vontade do papa, os leigos não deviam participar do concílio. ${ }^{5}$

Este e outros obstáculos tiveram que ser enfrentados a fim que muitas experiências, vivenciadas somente pelos leigos, pudessem ser devidamente interpretadas e incorporadas às orientações que foram elaboradas. Podemos citar as questões ligadas ao matrimônio e a certos aspectos da vida em sociedade.

É claro que não houve um aprofundamento pleno de todas as facetas da vocação dos leigos; contudo, as pistas lançadas pelo Concílio Vaticano II constituem uma etapa importante no processo de construção de uma Igreja mais comunitária e ministerial.

\subsection{O ensinamento das Constituições Apostólicas sobre o laicato}

Passamos, a partir de agora, a apresentar o que os documentos do concílio falaram sobre os leigos, de um modo específico. Sendo este o maior evento da Igreja no período contemporâneo, não podemos deixar de levar em consideração seus ensinamentos, que são ponto de partida para muitas renovações na ação da Igreja.

Comecemos pela Lumem Gentium (LG). Todo o capítulo IV desta constituição trata dos leigos, destacando o papel ativo e corresponsável que eles tem a desenvolver. Acentua-se a igualdade fundamental de todos os membros da Igreja a partir do batismo comum, da graça e das virtudes teologais. Afirma, ainda, que nas relações entre as várias vocações deve transparecer a atitude de serviço mútuo, a exemplo de Jesus, que veio "para servir e não para ser servido" (Mt 20,28). Para ilustrar que o autoritarismo não faz parte do sadio exercício da autoridade hierárquica, o texto cita Santo Agostinho que diz: "Atemoriza-me o que sou para vós; consola-me o que sou convosco. Pois para vós sou bispo, convosco sou cristão. Aquilo é um dever, isto é uma graça. O primeiro é um perigo, o segundo salvação". ${ }^{6}$

Outra afirmação forte é a que se refere à participação de cada cristão - e não somente do clero - na missão profética, sacerdotal e pastoral de

5 Cf. CHENU, M. D. Notes quotidiennes au concile. Paris: Cerf, 1995, p. $136 \mathrm{s.}$

6 AGOSTINHO. Sermão 340, 1. In: Compêndio do Vaticano II. Constituições, Decretos, Declarações. 6. ed. Petrópolis: Vozes, 1968, LG, n. 32, p. 79. 
Cristo. Sendo assim, o apostolado dos leigos não é somente uma 'ajuda' aos padres, que em tantas dioceses são pouco numerosos; é uma resposta ao chamado que o Mestre dirige a todos, pelo batismo e pela confirmação, para participarem de sua missão de salvação. ${ }^{7}$ Daí decorre que o engajamento de cada um na obra da evangelização é direito e consequencia natural dos sacramentos de iniciação e não somente uma concessão que a Igreja faz a alguns.

Também é interessante notar que a atuação dos leigos é reconhecida na Igreja e no mundo, embora seja considerada a necessidade toda particular de santificação das realidades sociais. ${ }^{8}$ Alguns comentam positivamente esta visão do leigo, como num Dossier de la Documentation Catholique, que diz: "nada evoca mais, neste texto, a definição negativa que considera o leigo unicamente em referência ao padre e ao religioso". ${ }^{9}$

Temos também análises mais críticas, como a de Schillebeeckx, que percebe no n. 31 do documento resquícios da antiga dicotomia: a Igreja aos clérigos, o mundo aos leigos. Ele chega a afirmar que na busca de definição do leigo, foi escolhido o caminho teológico menos indicado, isto é, o de uma descrição fenomenológica, que termina por definir os cristãos em geral e não os leigos. ${ }^{10}$

Contudo, o documento pede aos pastores que não só reconheçam, mas promovam a responsabilidade dos leigos na Igreja e deixem-Ihes liberdade e raio de ação. Encorajem-nos até para empreender outras obras por iniciativa própria. ${ }^{11}$

Numa sociedade cada vez mais complexa e secularizada é inconcebível não se considerar a experiência e capacidade dos leigos, sob pena de perdermos o passo da história, caindo num discurso antiquado e inoperante.

Somente para ilustrar, é bom saber que este capítulo recebeu 2.236 votos favoráveis dos bispos conciliares e apenas 08 contrários. Daí se

\footnotetext{
Cf. Id., LG, n. 33, p. 79.

Cf. Id., LG, n. 31, p. 77.

9 POTIN, J. (dir.). Les laïcs; leur mission dans l'Église et dans le monde. Colection Les Dossiers de la Documentation Catholique. Paris: Le Centurion, 1985, p. 19, tradução nossa.

10 Cf. SCHILLEBEECKX, E. La mission de l'Église. Bruxelas: CEP, 1969, p. 117.

11 Cf. Op. cit., LG, n. 37, p. 85.
} 
entende as inúmeras experiências que se desencadearam pelo mundo afora, sobretudo em nosso continente.

Será a partir destes pontos básicos apontados pela LG que os demais documentos vão desenvolver o discurso sobre os leigos.

A Constituição pastoral Gaudim et Spes (GS) trata dos leigos e de suas tarefas no capítulo IV da parte I, cujo título é 'Função da Igreja no mundo de hoje'. Os leigos são chamados a erradicar o descompasso existente entre fé cristã e compromisso social. A posição dos padres conciliares, reforçada por várias citações bíblicas, é claramente manifestada no seguinte texto: "Este divórcio entre fé professada e a vida cotidiana de muitos deve ser enumerado entre os erros mais graves de nosso tempo". ${ }^{2}$

No exercício de suas funções, os leigos devem agir em colaboração com outros membros da Igreja e da sociedade, dialogando construtivamente com pessoas de todas as opiniões. Tal opinião oferecia, já naquela época, as bases para uma postura aberta, numa sociedade que, efetivamente, tem se tornado cada vez mais pluralista.

Desenvolvendo suas atividades com competência e espírito de iniciativa, os leigos não devem esperar dos pastores as soluções aos problemas que se apresentam. Diz o documento: "Não julguem serem os seus pastores sempre tão competentes que possam ter uma solução concreta e imediata para todas as questões que surjam, mesmo graves, ou que seja esta a missão deles" ${ }^{13}$

Sem cair numa separação rígida de campos de ação, GS vai incentivar uma sadia autonomia do laicato a qual, em muitas situações concretas, constituiu o ponto de atrito entre membros da hierarquia e certos agentes de pastoral.

Não podemos deixar de notar que tais considerações referentes à missão do leigo em sociedade estão profundamente ligadas à nova base teológica.

A relação com o mundo secular só pode ser absorvida no conceito teológico do leigo, se a missão específica da Igreja já inclui em si mesma, uma relação eclesial com este mundo secular. A razão é que

12 Compêndio Vaticano II. Op. cit., GS, n. 43, p. 189.

13 Op. cit., GS, n. 43, p. 190.

132 Revista de Cultura TeológIcA - v. 20 - N. 79 - JUL/SET 2012 
o que distingue o leigo, teologicamente, deve distingui-lo também na sua relação com a Igreja. Do contrário, se introduziria um elemento alheio na definição eclesiológica. ${ }^{14}$

\section{2. $O$ ensinamento dos Decretos Conciliares sobre o laicato}

Vejamos agora os pontos principais do Decreto Apostolicam Actuositatem (AA), sobre o apostolado dos leigos. Logo no primeiro parágrafo fala-se do papel próprio e absolutamente necessário dos leigos. Buscando apoio em textos bíblicos (At 11,19-21; 18,26; Rom 16,1-16; Fil 4,3), o concílio afirma que o apostolado dos leigos, decorrente de sua vocação cristã, nunca pode faltar à Igreja. ${ }^{15}$

É uma afirmação bastante engajada, que reconhece também que em certos setores da sociedade, somente os leigos podem levar a mensagem de Jesus Cristo.

Ao falar da missão evangelizadora, o texto evoca a pluralidade dos serviços e ministérios suscitados pelo Espírito Santo em favor do crescimento da comunidade. Esta verdade, pregada com insistência pelo apóstolo Paulo, coloca os cristãos diante do apelo a partilharem os próprios carismas. Ao mesmo tempo, é preciso saber valorizar os carismas dos outros, numa atitude de dar e de receber; subentende-se que o apostolado é uma obra corresponsável.

A concepção de leigo apresenta uma clara evolução: ele não é somente um coadjuvante, um auxiliar, mas sim corresponsável pela obra missionária da Igreja. $O$ decreto conclama cada cristão a se deixar interpelar pelo brado paulino: "Ai de mim se eu não evangelizar" (1Cor 9,16).

Também é evidenciado o papel dos leigos na transformação das estruturas da sociedade. Imersos no mundo do trabalho, da política, da comunicação, do social, eles devem ser fermento de vida cristã no meio das realidades temporais a partir da justiça do reino de Deus. ${ }^{16}$

\footnotetext{
14 SCHILLEBEECKX, E. A definição do leigo cristão. In: BARAÚNA, G. (org.). A Igreja do Vaticano II. Petrópolis: Vozes, 1965, p. 998.

15 Cf. Compêndio Vaticano II. Op. cit., AA, n. 1, p. 529.

16 Cf. Op. cit., AA, n. 7, p. 537s.
} 
Ao citar os campos do apostolado, as comunidades da Igreja são especialmente destacadas. AA aprofunda a função dos leigos na transformação da paróquia numa verdadeira comunidade evangélica e evangelizadora. Ainda mais, mostra o valor do apostolado interparoquial, diocesano e extradiocesano. ${ }^{17}$ Alicerçado numa comunidade específica, o cristão deve sentir-se em comunhão com toda a Igreja.

Em seguida, destaca-se a 'família', constituída pelo Criador como princípio e fundamento da sociedade humana. Os pais cristãos são para os filhos os primeiros anunciadores e educadores da fé, e ajudam-nos com prudência na escolha da vocação. Daí podermos chamar as famílias assim edificadas nos valores evangélicos como autênticas "Igrejs domésticas". Aos jovens e crianças é reconhecido um lugar próprio na atividade apostólica. ${ }^{18}$

Várias orientações são dadas para o apostolado no ambiente social, que continua sendo um desafio imenso para a evangelização. Seja em nível local ou numa esfera mais abrangente, é urgente uma presença competente, coerente, organizada dos cristãos leigos, em cooperação com todos os homens de boa vontade.

A organização dos leigos é incentivada em grupos de interesse específico, conselhos, comissões, e outros. O mesmo espírito sinodal que se buscava na hierarquia é incentivado igualmente entre os leigos. A formação também é destacada no último capítulo. Tal prática tem se desenvolvido bastante nos últimos anos, proporcionando às pessoas o exercício mais consciente do diálogo, da comunhão e da participação.

Alguns peritos dizem que o documento AA poderia ter se beneficiado muito mais dos princípios emanados da LG e da GS, aplicando-os concretamente à nova situação dos fiéis na Igreja. John M. Miller afirma ser este o preço pago pelo decreto ter sido preparado cedo demais. ${ }^{19}$

Encontramos também no decreto Ad Gentes (AG), que trata da atividade missionária, outros elementos interessantes com respeito aos leigos. Podemos mesmo dizer que estava se inaugurando uma nova fase na missão da Igreja. Esta significava, até este momento, a ação evangelizadora do clero

\footnotetext{
Cf. Id., AA, n. 10, p. 542.

18 Cf. Id., AA, n. 11, p. 542s.

19 Cf. MILLER, J. M. La Teologia dopo I/ Vaticano II. Brescia: Morcelliana, 1976, p. 345.
}

134 Revista de Cultura TeológIcA - v. 20 - N. 79 - JUL/SET 2012 
e particularmente nas regiões além-fronteiras. Um sentido mais amplo vai se firmando, no tocante ao significado e aos atores da missão.

Embora a reflexão sobre os ministérios leigos estivesse ainda no seu início, o papel do leigo na formação da comunidade cristã é claramente reconhecido: "Para a fundação da Igreja e incremento da comunidade cristã fazem-se necessários vários ministérios, suscitados por vocação divina dentre a própria assembleia dos fiéis". ${ }^{20}$

O reconhecimento da pluralidade de agentes necessários à missão eclesial está na base de todo um desenvolvimento da dimensão ministerial, que tem se mostrado sempre mais abrangente. Se antes se dizia que o ministério consagrado representava a síntese de todos os ministérios, hoje ele é chamado a desenvolver o ministério da síntese.

A primavera dos ministérios em muitas regiões, como por exemplo, o Brasil, abriu novas fronteiras para a evangelização. As teorias materialistas sobre a morte de Deus e a superação da 'fase religiosa' do homem não foram comprovadas. $\mathrm{Na}$ visão do papa e de muitos agentes consagrados e leigos, o que deveria realmente morrer seria uma Igreja clerical e centralizadora, que não respondia mais ao dinamismo acelerado da sociedade.

AG realça o caráter indispensável da missão do leigo, como vemos claramente nesta afirmação:

A Igreja não se acha deveras consolidada, não vive plenamente, não é um perfeito sinal de Cristo entre os homens, se aí não existe um laicato de verdadeira expressão que trabalhe com a hierarquia. Porque o Evangelho não pode ser fixado na índole, na vida e no trabalho dum povo, sem a ativa presença dos leigos. ${ }^{21}$

Outro documento conciliar, Presbyterorum Ordinis (PO), embora não tratando especificamente dos leigos, ilumina ainda mais a nova fisionomia teológica do laicato. Já o primeiro capítulo começa destacando o 'sacerdócio santo e régio' de todo povo de Deus. Logo, o decreto tende a reduzir as distâncias entre clero e leigos. ${ }^{22}$

\footnotetext{
Compêndio Vaticano II. Op. cit., AG, n. 15, p. 371.

21 Id., AG, n. 21, p. 378.

22 Cf. Compêndio Vaticano II. PO, n. 2, p. 440.
} 
Considerando que o Concílio acentuou bastante as definições relativas aos bispos e aos leigos, poderia se pensar que a especificidade da vocação presbiteral estaria de certa forma diluída. Não é este o caso. Porém, o resultado pode ser negativo na medida em que se colocar o presbítero como o homem dos sacramentos. B. Sesboüé vê nesta prática um retorno à doutrina de Trento:

Não se pode ajudar aos padres quando são incentivados a pensar exclusivamente a partir de dois sacramentos; o da Eucaristia e o da Reconciliação. Esta é uma concepção minimalista de seu ministério. Trata-se mesmo de um desvio doutrinal $[\ldots]^{23}$

O padre não perdeu sua identidade, mas foi chamado a redescobrir-se como elemento de comunhão no seio do povo de Deus. Partilhando desta opinião, Sesboüé continua:

O que acaba de ser dito mostra que o acesso dos leigos a certas funções pastorais não ameaça em nada a especificidade do ministério presbiteral na totalidade de seu sentido e de suas tarefas. Pelo contrário, a rápida evolução da sociedade exigirá cada vez mais a qualidade dos padres e a melhor formação possível. ${ }^{24}$

Houve uma aproximação maior ao sacerdócio de Cristo, marcado mais pelo serviço que pela autoridade (Mt 20,28). Na companhia de todos os que se regeneraram na fonte do batismo, os presbíteros são irmãos entre irmãos, como membros de um só e mesmo corpo de Cristo, cuja edificação a todos foi confiada. ${ }^{25}$

Nesta perspectiva, a função de presidência da comunidade se torna promotora da participação de todos na missão da Igreja, numa sadia descentralização:

Da mesma forma entreguem com confiança tarefas aos leigos para o serviço da Igreja, deixando-lhes liberdade e possibilidade de agir convidando-os mesmo oportunamente a enfrentar obras também por sua iniciativa. ${ }^{26}$

\footnotetext{
${ }^{23}$ SESBOÜÉ, B. N'ayez pás peur! Op. cit., p. 95, tradução nossa.

24 Id., p. 113, tradução nossa.

25 Cf. Compêndio Vaticano II. Op. cit., PO, n. 9, p. 457s.

${ }^{26}$ Id., p. 458.
}

136 Revista de Cultura Teológica - V. 20 - N. 79 - JUL/SET 2012 
É um reconhecimento oficial da capacidade dos leigos de descobrir e assumir caminhos novos para a ação social e pastoral.

Várias décadas já nos separam da última sessão do Concílio Vaticano II, mas podemos certamente afirmar que o empenho em renovar e atualizar a ação da Igreja e o alcance dos vários ministérios continua sem tréguas. As idéias-força que norteiam a sociedade estão em contínua mutação, mas a inculturação deste legado eclesial deve ser assumida.

Um dos elementos que não pode faltar neste processo é a valorização da memória histórica. Combinando a fidelidade e a crítica construtiva, podemos encontrar nos documentos conciliares novas luzes para os posicionamentos atuais, desafiados pela pós-modernidade. Os documentos magisteriais e a Tradição em geral constituem uma fonte de primeira ordem para a vida eclesial, ao lado da Escritura e da realidade.

Hoje, mais que nunca, os pontos de referências são necessários. Cabe aos leitores descobri-los e escolhê-los, honestamente, permanecendo fiéis ao Espírito de verdade, que devemos acolher para que ele nos faça viver e nos guie em direção da verdade plena. ${ }^{27}$

\section{A RENOVAÇÃO DA AÇÃO ECLESIAL APÓS O CONCÍLIO VATICANO II NA AMÉRICA LATINA E NO BRASIL}

A partir do momento em que a concepção da Igreja como 'povo de Deus' e Comunhão ${ }^{28}$ passa a ser entendida como fato e tarefa, mudanças importantes aconteceram no tocante à ação, à reflexão e à organização eclesiais. O Concílio Vaticano II oficializou este anseio por novas práticas, embasado nas contribuições teológicas de diversos teólogos. Ele proporcionou, através das definições e indicações que vimos anteriormente, uma visão positiva do mundo. ${ }^{29}$

O próprio papa João XXIII, que convocara o Concílio, já havia urgido dos bispos latino-americanos, em 1958, uma decidida renovação da ação da Igreja. Antecipando importantes pistas de ação que proporia mais tarde,

27 GÉLAMUR, J. In: POTIN, J. (dir.). Les laïcs. Op. cit., p. 14, tradução nossa.

28 Cf. DULLES, A. A Igreja e seus modelos. São Paulo: Paulinas, 1978, p. 33s.

29 Cf. Compêndio do Vaticano II. Op. cit., GS, n. 1, p. 143s. 
ele destacava em sua mensagem a necessidade de uma clara visão da realidade; um plano de ação que, partindo da realidade, permitisse articular e somar forças e iniciativas; uma corajosa aplicação do plano; uma colaboração efetiva das Igrejas entre si. ${ }^{30}$

Ele reiterou seu apelo ao episcopado latino-americano em carta escrita a 08 de novembro de $1961 .{ }^{31}$ Seu sucessor, o papa Paulo VI, assumiu também as preocupações e particularíssimas solicitudes que 'o papa bom' demonstrara pela América Latina.

\subsection{Os leigos nos documentos conclusivos das assembleias episcopais latino-americanas}

Na Conferência de Medellín (1968), os leigos foram reconhecidos como participantes insubstituíveis na missão da Igreja, encarnando na realidade sofrida do continente as resoluções conciliares. ${ }^{32}$

A análise de Medellín é lúcida, seguindo a metodologia 'Ver, Julgar, Agir'. Ela parte de uma visão clara do momento histórico de então. A América Latina se caracterizava por uma situação de subdesenvolvimento, estampada na crescente marginalidade, alienação e pobreza. Eram os frutos de um verdadeiro neocolonialismo, ou seja, de uma estruturada dependência econômica, política e cultural em relação às metrópoles industrializadas, sobretudo os Estados Unidos da América.

Por outro lado aflora uma tomada de consciência dessa situação que se expressava, no Brasil e nos outros países do continente, em atitudes de protestos, de busca de libertação e de justiça social. O trabalho de base da AC especializada, do Movimento de Educação de Base (MEB), das primeiras Comunidades Eclesiais de Base (CEB's), comprova esta luta pela transformação da realidade de opressão.

A defesa do capitalismo e a luta contra o comunismo tornaram-se uma verdadeira obcessão, desencadeando um forte aparato repressivo através

30 Cf. QUEIROGA, G. F. Conferência Nacional dos Bispos do Brasil. Comunhão e Corresponsabilidade. São Paulo: Paulinas, 1977, p. 95.

31 Cf. Carta de João XXIII ao Episcopado da América Latina. In: REB. Petrópolis: Vozes, v. 22, n. 2, p. 461-463, [jun.] 1962.

32 Cf. DoCumento DE MEdellín, n. 10. São Paulo: Paulinas, 1979, p. 101. 
da Lei de Segurança Nacional (LSN). Caracterizava-se como uma autêntica ideologia elaborada nas academias de guerra, primeiramente nos Estados Unidos, em seguida em outros países do continente. Esta nova forma de dominação utilizava as forças militares, os meios de comunicação social e a educação pública, para incutir na população o medo de um sistema que ela nem mesmo conhecia.

O documento de Medellín supõe o peso desta situação em relação ao compromisso libertador e humanizador dos leigos latino-americanos. Uma insuficiente e/ou inadequada resposta a estes desafios é detectada pelos bispos que, no entanto não deixam de ressaltar o aspecto positivo:

Finalmente, não é possível desconhecer os valiosos serviços que prestaram e continuam prestando com renovado vigor os movimentos leigos à promoção cristã do homem latino-americano. Sua presença em muitos ambientes, apesar dos obstáculos e das dolorosas crises de crescimento, é cada vez mais efetiva e notória. ${ }^{33}$

Num segundo momento, o episcopado procurou aprofundar os fundamentos teológicos da ação laical. É a mesma teologia expressa nos documentos do Vaticano II, ilustrada por textos da LG e GS. Os leigos são considerados como participantes de direito à tríplice missão de Cristo e da Igreja: profética, sacerdotal e real.

Sem cair em reducionismos, o enfoque é dado a uma teologia militante, comprometida. Ser cristãos neste período histórico concreto do continente significava posicionar-se, romper com um espiritualismo desencarnado para viver uma fé que:

[...] está presente no compromisso temporal do leigo como motivação, iluminação e perspectiva escatológica, e dá sentido integral aos valores baseados na dignidade humana, na união fraternal e na liberdade. ${ }^{34}$

No terceiro momento, que é o da ação, Medellín incentiva os leigos a assumirem uma presença ativa nas estruturas de decisão da sociedade, a fim de influenciarem no processo de libertação e humanização. Apoia, também, sua inserção nos movimentos e organismos que trabalham pela justiça social e pela diminuição do desequilíbrio entre os povos.

33 DOCUMENTO DE MEDELLÍN. Op. cit., p. 101.

34 DOCUMENTO DE MEDELLÍN. Op. cit., p. 102. 
Nos anos seguintes, vários teólogos latino-americanos assumiram o trabalho de articular o discurso da ação, que se apresentava como uma luz nova que se projetava sobre o discurso teológico tradicional.

A CNBB assumiu oficialmente que o crescimento qualitativo do laicato teve uma importância capital na renovação preconizada pelo Vaticano II e assumida no documento de Medellín. Tal crescimento traduzia-se no espírito comunitário e na corresponsabilidade participada. ${ }^{35}$ Estas características não se perderam mesmo com a desestruturação e extinção da $A C$, cujos membros constituíram a maioria dos dirigentes das novas pastorais que foram nascendo das cinzas. A Pastoral Operária, Pastoral da Terra, Pastoral Indígena, Pastoral da Saúde, Centros de Direitos Humanos, entre outros: eis os herdeiros das várias expressões da AC. ${ }^{36}$

A partir deste momento veremos todas as diretrizes da CNBB incentivando a formação dos féis leigos e a viva consciência de que eles devem ter da sua responsabilidade nas tarefas da missão comum. Neste contexto histórico o papa Paulo VI pede que os leigos assumam de vez seu papel de sujeitos e se percebam como evangelizadores no meio do mundo e à frente de tarefas as mais variadas na ordem temporal, ${ }^{37}$ deixando a concepção pastoral arcaica que os via como destinatários da evangelização.

Posteriormente foi a vez de Puebla (1979) reconhecer o leigo como agente de comunhão e participação. ${ }^{38}$ É bom lembrar que, no Brasil, foi somente neste período que o documento de Medellín pôde ser realmente divulgado. Durante os anos 70, o país viveu amordaçado pelo Ato Institucional n. 05, através do qual o governo militar anulou a liberdade de expressão. As perseguições se multiplicaram, atingindo leigos, padres, religiosos e bispos. ${ }^{39}$

Puebla não trouxe grandes surpresas, como foi o caso de Medellín. Alguns teólogos apontam aspectos importantes que não avançaram, como o chileno Ronaldo Muñoz:

35 Cf. CNBB. Comunidade Mensal. N. 1. Brasília, 1974, p. 1136.

${ }^{36}$ Cf. PINHEIRO, J. E. In: CNBB. Leigos e participação na Igreja: reflexão sobre a caminhada da Igreja no Brasil. n. 45. São Paulo: Paulinas, 1986, p. 102s.

37 Cf. PAULO VI, Papa. Evangelii Nuntiandi: sobre a evangelização no mundo contemporâneo. 6. ed. São Paulo: Loyola, 1976, n. 70, p. 57.

38 Cf. Documento DE PUEBLA. São Paulo: Paulinas, 1979, p. 281.

39 Um relatório completo destas perseguições se encontra em SEDOC, n. 121, colunas 11611188, 1979. 
[...] perdeu-se a oportunidade de explicitar sistematicamente uma doutrina eclesiológica a partir da nossa realidade e ao serviço das urgências de nossa missão evangelizadora. ${ }^{40}$

Outra identificação de lacunas consideráveis:

Teriam sido naturalmente mais bem-vindas expressões de abertura positiva e de encorajamento com respeito à elaboração de uma autêntica teologia da libertação, à assimilação do marxismo científico pela reflexão cristã e à conformação de um projeto socialista condizente com nossa tradição religiosa. ${ }^{41}$

O mesmo autor cita, também, ganhos da maior importância:

(Puebla) indica que os pobres não são apenas objetos da evangelização, mas sujeitos ativos. Através deles o chamado da salvação se faz realmente universal [...]. O documento, desde o início, reconhece a validade das ceb's e na conclusão, depois de falar na criação do homem novo, indica como primeiro sinal de esperança a existência delas [...]. Puebla não inovou, mas expressou o que a Igreja já vem fazendo. E isso dá ao documento uma força especial, por sua coerência e adequação com as próprias experiências concretas. ${ }^{42}$

Muitos leigos ficaram perplexos diante da indefinição de uma 'terceira via' como alternativa ao capitalismo e ao comunismo, que foram condenados pelos bispos. O texto afirma claramente que a dimensão política é constitutiva do homem..$^{43}$ Mas muitos perguntavam qual é, afinal, o projeto social a abraçar. Tal hesitação pode ser um reflexo do posicionamento diverso das conferências episcopais frente aos governos nacionais. Em Puebla, a luta ideológica entre os bispos era bem evidente.

Mesmo tendo considerado criticamente estes mesmos pontos, Leonardo Boff elenca dez grandes avanços que perpassam o documento:

40 MUÑOZ, R. O capítulo eclesiológico das Conclusões de Puebla. In: REB. Petrópolis: Vozes, v. 39, n. 153, [mar.] 1979, p. 113.

41 BOFF, C. Puebla: Evangelização, Ideologias e Política. In: REB. Petrópolis: Vozes, v. 39, n. 153, [mar.] 1979, p. 103.

42 Id., p. 86.

43 Cf. DOCumento DE PUeBLA, n. 513. Op. cit., p. 218. 
1. A consagração do método de ver analiticamente, julgar teoricamente e de agir pastoralmente;

2. A dimensão social e política da fé;

3. A defesa e promoção da dignidade da pessoa humana;

4. A opção preferencial pelos pobres;

5. A promoção e libertação integral;

6. A religiosidade popular;

7. As CEB's;

8. A opção preferencial pelos jovens;

9. A promoção da mulher;

10. As três condenações: do capitalismo liberal, do marxismo coletivista e da ideologia da segurança nacional.

Boff conclui dizendo que Puebla se constitui numa vigorosa reafirmação do caminho da Igreja nos últimos dez anos. ${ }^{44}$

A tomada de posição oficial quanto ao papel do laicato na comunidade eclesial atingirá sua plena maturação no documento de Santo Domingo (1992), quando será oficialmente definido o protagonismo dos leigos na evangelização. ${ }^{45}$

Este documento demonstra séria preocupação com a crescente deserção dos católicos e sugere a visita domiciliar como um meio eficaz para trazê-los de volta. A Igreja, pastores e fiéis, sem descuidar do que estão mais próximos, deve sair ao encontro dos que estão afastados. ${ }^{46}$

É interessante notar que o documento de Santo Domingo, assumindo as palavras do beato João Paulo II, afirma a necessidade do querígma após 500 anos de evangelização na América Latina:

A partir da situação generalizada de muito batizados na América Latina que não deram a sua adesão pessoal a Jesus Cristo pela conversão primeira, impõe-se no ministério profético da Igreja, de modo prioritário e fundamental, a proclamação vigorosa do anúncio de Jesus morto e

44 Cf. BOFF, L. Puebla: Ganhos, Avanços, Questões Emergentes. In: REB. Petrópolis: Vozes, v. 39 , n. 153 , [mar.] 1979 , p. 50-52.

45 Cf. DOCUMENTO DE SANTO DOMINGO, n. 97. São Paulo: Paulinas, 1992, p. 121.

46 Cf. Id., n. 131. p. 137.

142 Revista de Cultura Teológica - V. 20 - N. 79 - JUL/SET 2012 
ressuscitado, raíz de toda evangelização, fundamento de toda autêntica cultura cristã. ${ }^{47}$

Diante das urgências da promoção humana e da evangelização da pessoa e das culturas, Santo Domingo trouxe uma linha pastoral inusitada:

[...] que todos os leigos sejam principais protagonistas da Nova Evangelização, da Promoção Humana e da Cultura Cristã. É necessária a constante promoção do laicato, livre de todo clericalismo e sem redução ao intra-eclesial. ${ }^{48}$

Uma verdadeira revolução na concepção da missão dos leigos na ação evangelizadora foi apontada neste documento. Se outrora eles eram objetos da pastoral e mais tarde auxiliares dos ministros ordenados, agora eles são considerados elementos vitais para afrontar os novos desafios que interpelam a Igreja Católica:

[...] que os batizados não evangelizados sejam os principais destinatários da Nova Evangelização. Esta só será levada a cabo se os leigos, conscientes de seu batismo, responderem ao chamado de Cristo a que se convertam em protagonistas da Nova Evangelização. ${ }^{49}$

Abria-se, deste modo, um novo horizonte para a atuação da Igreja, em todos os níveis.

Durante os últimos anos a insistência do protagonismo dos leigos na ação evangelizadora da Igreja no Brasil foi tamanha que, em 2007, durante a V Conferência Geral do Episcopado da América Latina e do Caribe em Aparecida, ${ }^{50}$ tal temática alcançou um destaque importante. Todos são convidados a serem discípulos-missionários; nesta tarefa os leigos ocupam um espaço privilegiado. O documento de Aparecida (DA) valoriza o papel do clero e do leigo dentro e fora da Igreja. Ele valoriza o trabalho conjunto já existente em várias comunidades, originado entre clero e leigos. ${ }^{51}$

Esta formação cristã que deve ser transmitida aos leigos para que eles saibam agir com incidência significativa nos diferentes campos da sociedade

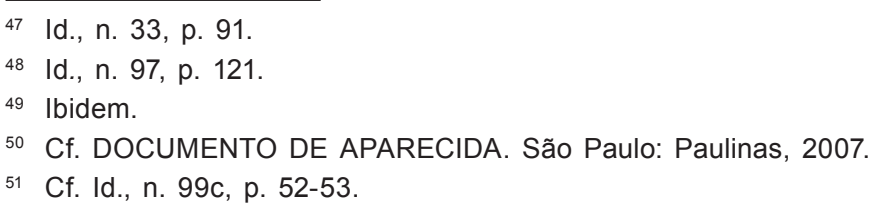


será ponto de destaque no DA. Ele destaca que a formação dos leigos deve contribuir, antes de tudo, para sua atuação como discípulos missionários no mundo, na perspectiva do diálogo e da transformação da sociedade..$^{52}$ A evangelização do continente não pode ser realizada sem a colaboração dos fiéis leigos.

Portanto, o documento diz sobre os leigos:

Hão de ser parte ativa e criativa na elaboração e execução de projetos pastorais a favor da comunidade. Isso exige, da parte dos pastores, maior abertura de mentalidade para que entendam e acolham o "ser" e o "fazer" do leigo na Igreja, que por seu batismo e sua confirmação é discípulo e missionário de Jesus Cristo. Em outras palavras, é necessário que o leigo seja levado em consideração com espírito de comunhão e participação. ${ }^{53}$

Os leigos possuem uma maneira singular de servir a Igreja e estar presente no mundo. Existe, então, um 'ser' e um 'fazer' que é próprio dos leigos. Bem como existe para os ministros ordenados. Cada um contribui com seus talentos e o resultado é colhido pela Igreja. Na grande ação evangelizadora o beneficiário dessa missão conjunta deve ser sempre o fiel afastado, abandonado e esquecido. Além disso, os leigos devem testemunhar a fé que professam na vida do dia a dia, mostrando coerência e autenticidade nos seus atos.

Os leigos também são chamados a participar na ação pastoral da Igreja, primeiro com o testemunho de vida e, em segundo lugar, com ações no campo da evangelização, da vida litúrgica e outras formas de apostolado, segundo as necessidades locais sob a guia de seus pastores. ${ }^{54}$

Fica evidente que a missão evangelizadora da Igreja é partilhada com os fiéis não ordenados. Os ministros ordenados são chamados a estarem dispostos a abrir para eles (os leigos) espaços de participação e confiar-lhes

52 Cf. Id., n. 283, p. 133.

53 Id., n. 213, p. 103.

54 Id., n. 211, p. 102.

144 Revista de Cultura TeológIcA - v. 20 - N. 79 - JUL/SET 2012 
ministérios e responsabilidades em uma Igreja onde todos vivam de maneira responsável seu compromisso cristão. ${ }^{55}$

A Igreja tem a necessidade de levar os valores evangélicos aos novos areópagos ${ }^{56}$ e centros de decisão de maneira positiva e propositiva. O leigo é chamado a ser o interlocutor entre a Igreja e a sociedade, e entre a sociedade e a Igreja. ${ }^{57}$ Por isso, ele é chamado a atuar como um verdadeiro sujeito eclesial.

Os leigos são incentivados cada vez mais a participarem de ações sociais e políticas nos diversos níveis e instituições. ${ }^{58}$ Eles são chamados a serem 'cidadãos cristãos' empenhados na busca de políticas públicas que ofereçam as condições necessárias ao bem-estar de pessoas, famílias e povos. ${ }^{59}$ Os fiéis leigos são igualmente chamados a serem pensadores e pessoas que estejam em níveis de decisão, evangelizando, com especial atenção e empenho, os novos areópagos. ${ }^{60}$ Os dois areópagos mais urgentes, elencados pelo documento, nos quais os leigos devem estar empenhados são: o mundo universitário e o mundo da comunicação. ${ }^{61}$

Cada batizado é portador de dons que deve desenvolver em unidade e complementaridade com os dons dos outros, a fim de formar o único corpo de Cristo, entregue para a vida do mundo. ${ }^{62}$

\section{CONCLUSÃO}

Sem dúvida nenhuma o grande responsável pelo desenvolvimento da teologia do laicato foi o Concílio Vaticano II, considerado o concílio dos leigos. ${ }^{63}$ Com o Vaticano II pudemos perceber uma significativa abertura

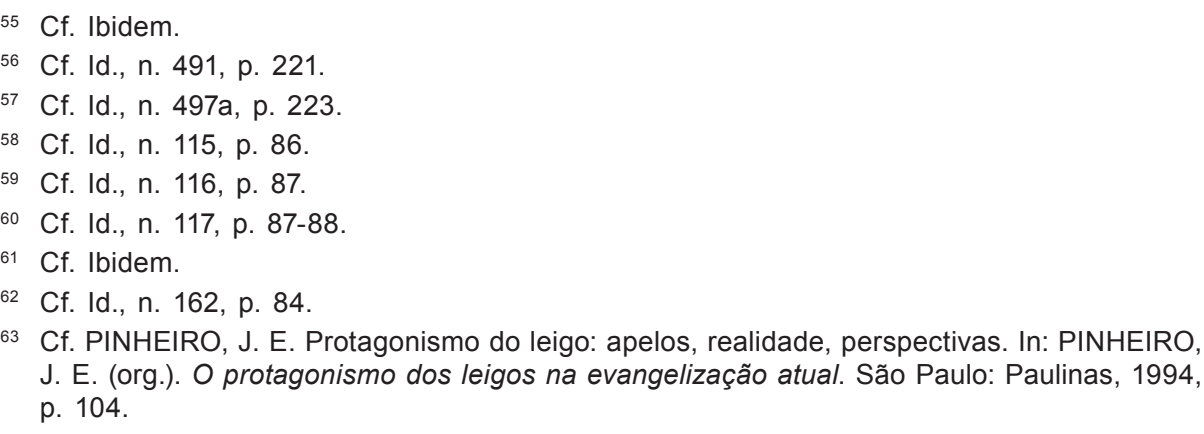


da Igreja aos fiéis leigos. O ideal de sacerdócio comum adquirido através do batismo começou de fato a ser colocado em prática. Aprendemos que para uma Igreja ser comunidade de comunidades é imprescindível o empenho por uma efetiva participação de todos os batizados nos destinos da comunidade, pela diversidade de carismas, serviços e ministérios. Trata-se da teologia dos ministérios.

Para que isso se transforme em realidade é necessário acolher a diversidade ministerial, na qual todos, trabalhando em comunhão, manifestam a única Igreja de Cristo, sejam eles leigos e leigas ou ministros ordenados. ${ }^{64}$ A Igreja, mais uma vez, interpela aos padres abrirem espaços para os leigos e confiar-lhes ministérios e responsabilidades. A diversidade de dons e carismas na unidade orgânica faz com que a Igreja descubra e integre os talentos que o Espírito presenteia aos fiéis, sejam eles leigos ou ministros ordenados.

Vocação, carisma e missão constituem aspectos fundamentais da teologia do laicato. Como se podem notar, esses elementos foram levantados pelo Vaticano II há exatamente cinquenta anos e ainda continuam vivos nas reflexões teológicas acerca dos leigos. São diversos os documentos conciliares que abordaram esta temática. Na América Latina, as Conferências Episcopais colocaram os leigos no centro das discussões. Foi a partir destas Conferências, e mais recentemente com o DA, que a teologia do laicato teve maior visibilidade no Brasil.

\section{BIBLIOGRAFIA}

COMPÊNDIO DO CONCÍLIO VATICANO II. Constituições, Decretos, Declarações. Constituição Dogmática Lumen Gentium. 6.ed. Petrópolis: Vozes, 1968. .Constituição Pastoral Gaudium et Spes. 6. ed. Petrópolis: Vozes, 1968. .Decreto Apostolicam Actuositatem. 6. ed. Petrópolis: Vozes, 1968. .Decreto Ad Gentes. 6.ed. Petrópolis: Vozes, 1968. .Decreto Presbyterorum Ordinis. 6. ed. Petrópolis: Vozes, 1968.

II CONFERÊNCIA GERAL DO EPISCOPADO LATINO AMERICANO. DOCUMENTO DE MEDELLÍN. São Paulo: Paulinas, 1979.

${ }^{64}$ Cf. DOCUMENTO DE APARECIDA, op. cit., n. 104a. p. 80.

146 Revista de Cultura TeOlógICA - v. 20 - N. 79 - JUL/SET 2012 
III ${ }^{a}$ CONFERÊNCIA GERAL DO EPISCOPADO LATINO AMERICANO. DOCUMENTO DE PUEBLA. São Paulo: Paulinas, 1979.

IV a CONFERÊNCIA GERAL DO EPISCOPADO LATINO AMERICANO. DOCUMENTO DE SANTO DOMINGO. São Paulo: Paulinas, 1992.

Va CONFERÊNCIA GERAL DO EPISCOPADO LATINO AMERICANO E DO CARIBE. DOCUMENTO DE APARECIDA. Brasília: Edições CNBB, 2007.

ALBERIGO, A.; ALBERIGO, G. Giovanni XXIII. II concilio della speranza. Padova: Ed. Messaggero, 1985.

BARAÚNA, G. (org.). A Igreja do Vaticano II. Petrópolis: Vozes, 1965.

BEOZZO, J. O. (ed.). Cristianismo y Iglesias de América Latina en vísperas del Vaticano II. San José: DEI/CEHILA, 1992.

CHENU, M. D. Notes quotidiennes au concile. Paris: Cerf, 1995.

CNBB. Comunidade Mensal. n. 1. Brasília, 1974.

.Leigos e participação na Igreja: reflexão sobre a caminhada da Igreja no Brasil. n. 45. São Paulo: Paulinas, 1986.

DULLES, A. A Igreja e seus modelos. São Paulo: Paulinas, 1978.

LAMBERIGTS, M.; SOETENS, C. A la veille du Concile Vatican II. Leuven: Bibl. van de faculteit der Godgeleerdheid, 1992.

MILLER, J. M. La Teologia dopo // Vaticano II. Brescia: Morcelliana, 1976.

PAULO VI, Papa. Evangelii Nuntiandi: sobre a evangelização no mundo contemporâneo. 6. ed. São Paulo: Loyola, 1976.

PINHEIRO, J. E. (org.). O protagonismo dos leigos na evangelização atual. São Paulo: Paulinas, 1994.

POTIN, J. (dir.). Les laïcs; leur mission dans l'Église et dans le monde. Colection Les Dossiers de la Documentation Catholique. Paris: Le Centurion, 1985.

QUEIROGA, G. F. Conferência Nacional dos Bispos do Brasil. Comunhão e Corresponsabilidade. São Paulo: Paulinas, 1977.

REB. Petrópolis: Vozes, v. 22, n. 2, p. 461-463, [jun.] 1962.

.Petrópolis: Vozes, v. 39, n. 153, [mar.] 1979.

Revue des Sciences Religieuses de Strasbourg. Estrasburgo: [s.n.], n. 1, t. 62, p. 62 e 69, 1988.

SCHILLEBEECKX, E. La mission de l'Église. Bruxelas: CEP, 1969.

SESBOÜÉ, B. N'ayez pas peur! Paris: Desclée de Brouwer, 1996. 